\title{
Qualitative Characteristics of Financial Reporting: An Evaluation According to the Albanian Users' Perception
}

\author{
Albana Gjoni-Karameta ${ }^{1}$ \\ Elona Fejzaj ${ }^{1}$ \\ Ahmad Mlouk ${ }^{2}$ \\ Kristina Sila ${ }^{1}$ \\ ${ }^{1}$ Faculty of Economy and Agribusiness, \\ Agricultural University of Tirana, Rruga Paisi Vodica 1025, Tirana, Albania \\ ${ }^{2}$ Staffordshire Business School, Staffordshire University, \\ College Rd, Stoke-on-Trent ST4 2DE, United Kingdom
}

DOI: https://doi.org/10.36941/ajis-2021-0151

\begin{abstract}
The last 20 years' changes in accounting has led to an essential review process of national accounting standards due to the main objective of improving financial reporting information for stakeholders. Financial reporting as a communication tool has become extremely important for appropriate decision making to economic reporting entities and also financial information users such as analysts, creditors, managers, auditors and government agencies in Albania and all over the world. The absence of a generally accepted definition for qualitative financial reporting has created a gap for continuous research on this matter. The main objective of this study is to examine users' perception of qualitative financial reporting, toward their perceptions of some selected qualitative characteristics of financial statements. This study aims to determine the attitudes of financial statements' users toward the importance of qualitative characteristics of financial information reported on these published financial statements. The chosen qualitative characteristics were relevance, faithful representation, comparability, timeliness, verifiability and understandability. An opinion survey was conducted on three hundred external users of financial statements, such as managers, bank officers, financial analysts, government officers and auditors. Each single characteristic has been operationalized using a structured questionnaire, and a five point Likert type scale was used. Selection process of qualitative characteristics of reported financial information will be based on the data taken from conceptual framework of international financial reporting standards published by the International Accounting Standards Board in a continuous process of improving financial reporting. This research examined primary data taken through an opinion survey directed to three hundred daily users of financial statements 'information, reported by economic entities in Albania. Results of the study show a very strong positive correlation between users 'perception and qualitative characteristic of faithful representation, a relatively strong positive correlation with relevance, comparability and understandability, and a moderate correlation with timeliness and verifiability. Users of financial reporting in Albania generally have a very positive attitude towards the qualitative characteristics of financial reporting.
\end{abstract}

Keywords: Financial Reporting, Qualitative Characteristics, Financial Statements, Users of Financial Information, International Financial Reporting Standards 


\section{Introduction}

As a connecting point between internal and external parties within an organization, financial reporting and its quality has been and still is of huge concern to everyone involved in this process. The absence of a certain indicator in order to measure the quality of financial information, has led to different perceptions of users about what information to consider important. The objective of this study is the operationalization of the quality of financial reporting using a structured questionnaire according to qualitative characteristics of financial statements defined by the conceptual framework of IFRS and FASB such as: relevance and faithful representation of financial reporting, and also the comparability, verifiability, timeliness and understandability. There are many other qualitative characteristics which enhance quality to financial information, such as materiality and consistency, materiality and neutrality. Also, the perception of users of financial information in Albania will be evaluated based on some main issues like: What is their attitude toward different characteristics like relevance and faithful representation and then further on more qualitative characteristics that enhance fundamental characteristics, like comparability, consistency, understandability and reliability? Problems that users of financial information are dealing with is very actual and consistent in Albania. The importance of financial information derived from financial statements is crucial to both external and internal users for decision making. This issue needs a better understanding in order to generate a proper answer to the problems of low quality of financial information. The hypotheses risen for the study research present a logical connection between the variables and are easily testable with the chosen research method. This paper aims to make a theoretical contribution which is of interest to all users of financial reports. We must emphasize that there are only a few studies in Albania about the perception of users of financial statement's information, especially in terms of qualitative characteristics of financial statements reported by economic entities in Albania. The purpose of this paper is to study whether users of financial reports in Albania have a positive attitude towards the qualitative characteristics of information published by local economic entities and also to clearly define their perception regarding the financial statements prepared and published. This research is carried out in Albania and it investigates the perception of users of financial statements and reports with regards to the following six qualitative characteristics: relevance, faithful representation, comparability, verifiability, timeliness and understandability.

\section{Literature Review}

Financial reporting is one of the main pillars in building modern business. In addition to the legal requirements for financial reporting, what needs to be understood is the untapped potential in this regard and the power that good knowledge of it can bring. More transparent capital market, minimized uncertainties, true picture of the condition of the economic entities' financial position, disclosure of information on management matters and many other advantages come precisely as a result of the accurate publicly available accounting information. The accounting system as an official information language for representation of financial position, net income and net cash flow result, is a fundamental basis for capital market actors' decisions (Rostami \& Salehi 2011). Financial reporting is the financial result of an organization that is released to the public. Financial reporting usually includes the following elements: Financial statements, which include statement of financial performance (income statement), statement of financial position (balance sheet), statement of changes in equity and cash flow statement; financial statement disclosures, which provides additional information on certain topics, defined by the relevant accounting framework; annual reports issued to shareholders; prospectuses issued to potential investors regarding potential risks involved when investing in different securities by the organization. The main purpose of financial reporting is to provide high quality information to stakeholders, mainly of a financial nature, useful for economic decision making (Al-Dmour, Abbod, Al-Dmour, 2017). The qualitative financial information is crucial for right decisions in capital markets. (Obaidat, 2007). According to the Financial Accounting 
Standards Board (FASB, 2008), financial reporting objectives emphasize the importance of the quality of financial information, because only when this objective is set, qualitative characteristics of financial statements can be determined. Financial statements 'users provide information in retrospective and use it to predict the future events; the main focus of financial reports is to provide information about profitability indicators. and their key components. The value of financial accounting is mainly determined by its quality (Pounder, 2013). Studying the literature, it is noted that on the one hand, the quality of accounting information can be seen as the accuracy with which financial reports convey information to current and potential investors about projected cash flows (Pounder, 2013). Whereas, on the other hand, the quality of reporting refers to the degree to which a company's financial reports show its economic condition and its performance during the reference period (Aifuwa, Embele, Saidu 2018). The importance of good accounting information is considered essential to enhance the qualitative aspects of financial reporting. This quality is related to the degree to which relevant information has the ability to influence the decision-making process by users of financial statement. Based on the existing literature, relevance is operationalized precisely by using four items referring to predictive value of information, its confirmatory value, usefulness and its feedback value (Jonas \& Blanchet, 200o). Financial information has predictive value if it can be used by users to predict future results and confirmatory value if it brings feedback (confirms or changes) to previously made estimates (IFRS, 2010). However, to enhance faithful representation, financial information must be complete, impartial and error-free (IFRS, 2010). For financial information to become complete, financial reports must include all the information that represents faithfully the economic eves, with all the notes that explain methods and accounting practices used. For financial information to become neutral, financial information should not be manipulated in any way to influence users' decisions. For financial information to become error-free, financial reports should have no errors in describing a phenomenon and the process in which financial information was produced. No faithful representation of an insignificant phenomenon nor an unfaithful representation of a relevant phenomenon helps users to make good decisions (Soyinka, Fagbayimu, Adegoroye, Ogunmola, 2017). Information derived from reported financial statements can be comparable between different periods or between different companies in the same reporting period, and this characteristic makes information relevant for decision makers (IFRS, 2010). Comparability is a qualitative feature that enables users to identify and understand similarities and differences between financial statements items (IFRS, 2010). Verifiability helps to assure users of financial statements that the financial information faithfully presents the economic phenomena it intends to present. (IFRS, 2010). Jonas and Blanchet (2000) are considered to be the first to use the qualitative characteristics as a measure to assess the quality of financial reporting based on the conceptual framework of the FASB (1980) and the IASB (1989). They focused on two main perspectives to make this possible: the first perspective defines the quality of financial reporting regarding the usefulness of financial information to users (broadly defined as investors and creditors) of this information while the second perspective relies on the notion of shareholder / investor protection. In that context, quality financial reporting aims to provide information to users that is sufficient for their needs, transparent and competent. McDaniel, Martin, and Maines (2002) also supported this method by developing the assessment of financial reporting quality methodology for evaluating and comparing information's quality in different organizations. In 2008, the IASB launched a project entitled "An Improved Conceptual Framework for Financial Reporting". Under this framework, characteristics of financial statements make the financial information to be useful, such as relevance, reliability, comparability, verifiability, timeliness, and understandability (FASB, 20o8). Following these studies, it will be mentioned how the previous literature has operationalized these qualitative characteristics which became one of the strongest bases to enable a way of measuring the quality of accounting information and financial reporting. Relevance, or as it is referred to in the paper, the "importance" of financial information, has been operationalized in the context of its predictive value and its confirmatory value (IFRS, 2010). The tendency of researchers to focus on the quality of earnings rather than the quality of financial reporting, neglects the importance of non-financial information 
and excludes the possibility of using "future financial information", for users of the annual reports, for example future transactions (Beest, Braam, Boelens, 2009). Therefore, in the questionnaire used in this paper, this factor will be fully included, it will take into account a broader perspective including financial and non-financial information. According to the existing literature, the faithful representation or reliability of financial reporting information is measured with the help of the following components in relation to: neutrality, completeness, lack of material error, verifiability and control (Beest, Braam, Boelens, 2009; Tsoncheva, 2014). The reason why these elements should be reviewed has to do with the fact that all phenomena and transactions that occur in an economic entity are variable over time, so the annual report must document each event and transaction with care and accuracy (Al-Dmour, Abbod, Al-Dmour, 2017). Qualitative feature of comparability on the other hand is the feature that allows users to identify and understand similarities and differences between two economic phenomena, two or more financial measures of different economic entities in the same reporting period or different reporting periods for the same company. The operationalization of comparability can be determined according to the existing literature. Beest, Braam, Boelens (2009) used six components, four of which refer to consistency in using the same accounting policies and procedures from period to period within a company and two other components are used to measure comparability in a single period between existing companies in the market, all based on what is referred to as sustainability (Tsoncheva, 2014).

Subsequently Cuong and Ly (2017) also assessed comparability through information on changes in accounting policies, information on changes in accounting estimates, relevant comparative information and the impact of changes in accounting policies, financial indices and reports, and information on shareholders' investments, industry and competition related information. Another qualitative improvement feature is timeliness, a factor that has been operationalized in several ways in various studies. H Aifuwa, K Embele, M Saidu (2018) argue that timeliness increases the quality of financial reporting as it ensures that the information provided is available to decision makers before it loses its positive impacts. According to the latter, it is estimated as the difference between the end of the year and the date of issue of the auditor's report. According to Cuong and Ly (2017), timeliness is operationalized using frequency of financial reports, it is linked to the time it takes for the financial information to be published. Beest, Braam, Boelens (2009) choose to estimate this factor using the natural logarithm of the number of days between the end of the year and the 'signing' of the auditors' report after the end of the year. The following qualitative characteristic of understandability refers to the note that the information in the financial statements is presented in such a way that it is immediately understandable by users of financial statements. According to Vokshi (2017), in order to promote understanding, standard-setters seek to make sure that the terminology and format of presentation of financial statements are consistent, so that users know how to read a set of financial statements, and also to be able to read the presented information generated by other economic entities as well. Tsoncheva (2017) operationalizes understandability through four main components: good structuring of annual reports, balance sheet entries and income statement, availability of tables and graphs, and finally the use of accurate terminology. The last improvement feature identified and assessed as important for qualitative financial reporting is verifiability. Verifiability is s the extent to which information is reproducible, it means that the information leads the users at the same decisions (S Hasan, S N Abdullah, S Z Hossain, 2014). The usefulness of information increases if it is verifiable. Verifiability helps to guarantee users that the accounting information provided accurately represents the economic phenomena they intend to describe, so financial reporting should be based on facts unaffected by the subjective judgment of the person making the measurement or evaluation of financial reports Aifuwa, Embele, Saidu 2018). One of the ways to verify financial information is through auditors. In addition to verifying the accuracy of the financial statements, the auditors will also review the company's accounting methods and procedures to verify that the company has taken appropriate steps to prevent fraud. The audit assures investors and creditors that the company's funds are properly managed. Auditors protect the public from investing in companies that use corrupt business practices or attempt to mislead investors with false financial statements. (Brenner, 
2019). The operationalization of the above features has been used in a number of studies by authors who aimed to ascertain the perception of users of financial reports. Most of them are based on the qualitative characteristics defined by the Conceptual Framework of the International Accounting Standards Board (2010). Rostami and Saleh (2011) analyzed the relevant components for each of the basic and improving quality characteristics, seen in the specific environment of Iran according to opinions from the top three financial reporting groups, including: professional accountants, users, and preparers of accounting information. They designed an appropriate questionnaire with some questions about the real state of qualitative characteristics in securing Iran's current financial reports. The collected data were tested by post-hoc tests such as Kruskal-Wallis, and Friedman. They concluded that the presence of qualitative characteristics plays an important role in increasing the level of quality of reporting, although it turnes out that the perception of preparers towards qualitative characteristics of accounting generally differs from that of members of the accounting profession. A year later S Tasios (2012) investigated auditors' perception of the quality of financial reports and identified the main factors that influence and improve the quality of financial reports. This study was conducted in Greece and concluded that auditors perceive qualitative characteristics as important elements of the quality of financial reports. Maher, Fakhar and Jafari (2015) examined the perception of managers of Iranian medical universities and whether the submitted financial reports contain qualified information. The result of their study was consistent with previous studies, their findings showed once again that the information presented in the financial reports should be of appropriate quality, honest, understandable, timely, verifiable and comparable. Mbobo and Ekpo (2016), followed by Soyinka, Fagbayimu, Adegoroye and Ogunmola (2017), examined financial users' perceptions regarding the quality of financial reporting and the use of qualitative characteristics in measuring the quality of financial reporting. Their purpose was to study how the qualitative characteristics set out in the conceptual framework introduced by IASB can be operationalized, IASB (2010). The results showed that respondents perceived characteristics such as reliability and faithful representation had greater potential to improve the quality of financial reporting, but without neglecting other supporting features such as relevance, comparability and understandability. While Soyinka, Fagbayimu, Adegoroye and Ogunmola (2017), contrary to the above studies, concluded that the majority of respondents do not rely on financial reports provided by companies due to the fact that their needs for information as stakeholders were not met as required. In conclusion, the paper recommends that in order for financial reports to be more meaningful and of significant benefit to the general public, information should be produced in the most reliable way, it should be understandable, comparable, timely and verifiable. In recent years, a few of studies have been conducted regarding the quality of financial reporting and the levels of disclosure in the annual reports in Albania. But most of these studies did not include users' perceptions especially of the qualitative characteristics of financial reporting in entities in Albania. The World Bank and SECO (2015) undertaken the "Project for Increasing the Quality of Financial Reporting". The survey conducted in this project provides the first empirical data on Albanian respondents' perceptions of financial reporting. The survey is aimed at different user groups, such as: government agencies, public and private financial institutions, non-financial institutions, academia, etc. The overall survey results show that the quality of financial reporting at that time has improved significantly compared to five years ago. However, these responses indicate that financial reporting needs to be improved through more detailed information, more disclosed data, and clearer relationships with related parties, as well as more detail on risk exposure and risk management to determine appropriate actions. Reduce financial risks. More recently Deloitte Albania (2018) with the support of the Ministry of Finance and Economy and the World Bank launched the survey on 'Financial Reporting in Albania'. Surveys conducted on users and preparers of financial reports in the country yielded the following results: $44 \%$ of users reported a lack of explanatory and risk notes is among the shortcomings of financial reporting. According to accounting experts (User Survey Deloitte 2018), this was considered a positive indicator, as it showed that business leaders were 'hungry' for quality financial reports which creates space for the inclusion of details and promotes the continuous improvement of 
financial reporting. In 2017 Krupka and Muzyka uncovered a few basic subjective characteristics of announcing data focused on towards shoppers and fundamental for decision-making. A number of basic subjective characteristics and impediments of detailing data for administration were comparatively evaluated. These characteristics included comparability, relevance which comprises reliability, feedback, timeliness, independence and verifiability. Among these characteristics, comparability of published data was singled out. In 2016, Morosan Danila and Grigoras focused on the importance of the qualitative characteristics of information that professional accountants pay attention to when preparing financial reports. They also compared the handling of qualitative characteristics of accounting information between the Romanian accounting framework and the European and international accounting frameworks. In 2021, Mohd Hussin, Zainol, Tengku Arifin and Samsuri tried to check the qualitative characteristics and quality of the financial reports of Malaysian listed manufacturing companies. Their research explored whether qualitative features can promote financial utility by providing high-quality financial reporting information. In 2017, based on the Chinese market, Zheng and Chen carefully selected five qualitative characteristics (faithful representation, relevance, timeliness, comparability, understandability) and the corresponding secondary indicators to study the quality of financial reports, using the analytical hierarchy process and methods of evaluation, their research established a system for evaluating the quality of qualitative financial reports in China. In 2019 in Mbawuni studied the views of top and middle management on the financial reporting quality of Ghanaian companies after the adoption of the International Financial Reporting Standards (IFRS). In accordance with the literature, a fivedimensional financial reporting quality questionnaire was developed for this research. Generally, managers perceived qualitative characteristics to be important, but timeliness appeared to be the less rated characteristic. In 2019, Chen and Gong studied the impact of accounting comparability on the quality of financial reports and the extent to which users of financial statements understand the impact of business accruals. They predicted that comparability could improve the information environment, not only by improving managers' ability to more accurately estimate accrued expenses and ascertain their private information, but also by improving investors' understanding of accounting expenses.

\section{Methodology}

The main objective of this study is to examine whether users of financial information have a positive attitude toward qualitative characteristics of financial statements reported by economic entities in Albania. Data for this study have been collected from an open survey conducted during the first three months of 2021. Before distribution, the questionnaire was piloted, which included four professionals with extensive experience in accounting and financial reporting: an external auditor, a financial accountant, an academic researcher, and a financial analyst. Based on feedback provided the structure of the questionnaire was improved. Primary a total of 380 respondents were selected, but finally only 300 of them answered. A total of Survey questions were determined based on the existing theory about financial reporting published by IASB (2010). According to the literature review we can find different scales of assessing the users' attitude toward a specific matter. One of the most used research tool is the Likert scale (1932). Likert scale has been used in this study to assess the attitude of users of financial information toward qualitative characteristics of financial statements reported periodically by Albanian economic entities The questionnaire consists of three parts. The first part of the questionnaire includes questions about the demographic characteristics of the participants (gender, age, occupation, education, years of work experience, professional qualification. The second part aims to capture the information from each financial report, using the five-point Likert scale. In addition, each interviewee was asked to conduct an overall assessment of the quality of the financial reports of the Albanian company, including reports to networks, importance factors leading to and quality of which can improve the quality of the report. Finally, participants were asked about their opinions on the adoption of IFRS, the improvement of national standards, and their own definition of 
the term "financial information quality". The third part of the questionnaire aims to gain an in-depth understanding of the perceptions of users through questions related to each qualitative feature of financial information, combined with questions based on the quality of financial information. Finally, participants can choose to write comments in order to express their opinions and provide their feedback on the survey. We use regression methods to estimate the relationship between different research variables.

As far as the characteristics of the respondents are concerned, in terms of gender, $73 \%$ of the respondents are women and $27 \%$ are men. In terms of age, $48 \%$ of people are under 35 years old, $28 \%$ are between $24 \%$ and 50 years old, and $27 \%$ are over 50 years old. $60 \%$ of respondents have less than 10 years of work experience and $40 \%$ of respondents have more than 10 years of work experience. $23 \%$ of those surveyed were managers, $34 \%$ were bank officials, $18 \%$ were auditors, and $25 \%$ were financial analysts. We considered as dependent variable the users' perception about quality of financial reporting in Albania, variable (y). On the other hand, each of the six qualitative characteristics of reported financial statements has been operationalized based on the literature review, in this context variable (x) will explain the dependent variable. Study hypotheses were raised for each qualitative characteristic such as relevance, faithful representation, comparability, timeliness, understandability and verifiability to estimate the attitude of users in presence of these qualitative characteristics. The linear regression formula used for this study is $\left(y i=\beta o+\beta_{1} X i+\varepsilon i\right)$, other statistical indicators calculated are the determination coefficient $\left(R^{2}\right)$ and the correlation coefficient $(R)$. This method contributes in achieving the study objective and giving a clear distinctive result that helps us to get the right answers to the research questions. The study survey was directed to regular users of financial information provided by reported financial statements in Albania. Target group included managers, bank officers, government officers, financial analysts, investment analysts, and auditors. A total of 300 users answered the survey and provided us with significant useful data for the study.

Variables considered for this study are as follow:

Dependent Variable (Y) - Users 'perception for quality of financial reporting in Albania;

Independent Variable (X) for first hypothesis - Qualitative Characteristic of Relevance;

Independent Variable (X) for second hypothesis - Qualitative Characteristic of Faithful Representation;

Independent Variable (X) for third hypothesis - Qualitative Characteristic of Comparability

Independent Variable (X) for fourth hypothesis - Qualitative Characteristic of Timeliness

Independent Variable (X) for fifth hypothesis - Qualitative Characteristic of Understandability

Independent Variable (X) for sixth hypothesis - Qualitative Characteristic of Verifiability

For each qualitative characteristic we analysed data through the regression model. This study aimed to asses separately the perception of users toward each single qualitative characteristic. Statistical measures have been calculated and interpreted to show if there is a statistically significant relationship between variables, and if this is a functional one.

\section{Results}

The following analysis estimated results for 300 users of financial reports who have expressed their attitudes towards six qualitative characteristics of the accounting information made available to them. Each feature taken into consideration consisted of several sub-issues expressed in the form of statements that were selected based on the literature reviewed for this paper in order to operationalize each of them. Respondents rated each statement from strongly disagree to fully agree. Relevance: One of the fundamental qualitative characteristics of reported financial statements was operationalized based on 7 questions $\left[R_{1}, R_{2}, R_{3}, R_{4}, R_{5}, R_{6}, R_{7}\right]$, to understand how important this characteristic is in the users perception. Faithful Representation: the second fundamental qualitative characteristic of reported financial statements was operationalized based on 5 questions ( $F_{1}, F_{2}, F_{3}$, $\mathrm{F}_{4}, \mathrm{~F}_{5}$ ), to understand how important this characteristic is in the users perception. Comparability: this additional qualitative characteristic that enhances the quality of financial reporting was 
operationalized based on 6 questions $\left(C_{1}, C_{2}, C_{3}, C_{4}, C_{5}, C 6\right)$, in order to estimate the attitude of users toward this characteristic. Timeliness: this additional qualitative characteristic that also enhances the quality of financial reporting was operationalized based on 2 questions $\left(\mathrm{T}_{1}, \mathrm{~T}_{2}\right)$, in order to estimate the attitude of users toward this characteristic. Understandability: this additional characteristic was operationalized using 7 declarations from users of financial statements $\left(U_{1}, U_{2}, U_{3}\right.$, $\left.\mathrm{U}_{4}, \mathrm{U}_{5}, \mathrm{U} 6, \mathrm{U}_{7}\right)$. Verifiability: The last characteristic was operationalized using 2 statements of users $\left(\mathrm{V}_{1}, \mathrm{~V}_{2}\right)$. This operationalization was based on whether the annual reports are verified and assessed from internal and external auditors.

\subsection{Qualitative Characteristic of Relevance}

Hypothesis that have been raised for the first qualitative characteristic are as follows:

Ho: There is no significant relationship between the perception of users about quality of financial reporting in Albania and the qualitative characteristic of Relevance.

$\mathrm{H}$ : There is a significant relationship between the perception of users about quality of financial reporting in Albania and the qualitative characteristic of Relevance.

We developed correlation and linear regression earlier as a way of expressing the strength and linear relationship between two variables: $\mathrm{Yi}=\beta \mathrm{o}+\beta_{\mathrm{X}} \mathrm{Xi}+\varepsilon \mathrm{i}$

Table 1: Results of the model for Relevance (First Qualitative Characteristic)

\begin{tabular}{ccccc}
\hline Model & $\begin{array}{c}\mathrm{R} \text { (Coefficient of } \\
\text { Correlation) }\end{array}$ & $\begin{array}{c}\mathbf{R}^{2} \text { (Coefficient of } \\
\text { Determination) }\end{array}$ & $\begin{array}{c}\text { Adjusted R } \\
\text { Square }\end{array}$ & $\begin{array}{c}\text { Std. Error of the } \\
\text { Estimate }\end{array}$ \\
\hline 1 & 0.861 & $\mathbf{0 . 7 4 2}$ & 0.706 & 0.54397 \\
\hline
\end{tabular}

Source: Author

In this case $\mathrm{R}=0.861$; the coefficient of correlation with value between 0.7 and 0.9 shows that variables have a strong positive relationship. According to the results provided from the regression model we conclude that there is a strong correlation or a functional link between the perception of users of reported financial statements about qualitative financial reporting and relevance as a fundamental qualitative characteristic. Coefficient of Determination $\mathrm{R}^{2}=0.742$ shows the proportion of the variance for a dependent variable that's explained by an independent variable or variables in a regression model. In our case $74.2 \%$ of users' perception of the quality of financial reporting is attributed to the qualitative characteristic of relevance for influencing decisions. This value indicates that the link is strong and meaningful. This clearly shows that users hold a positive attitude towards the independent variable X (relevance). Specifically, relevance is linked to the following statements that represented its presence as follows: financial reporting provides valuable future information, the use of current market values as a measurement basis, information on profitability levels for entities and finally submission of annual reports according to the requirements of the accounting regulatory bodies.

\subsection{Qualitative Characteristic of Faithful Representation}

Ho: There is no significant relationship between the perception reported financial statements' users about qualitative financial reporting in Albania and the qualitative characteristic of faithful representation.

Hi: There is a significant relationship between the perception reported financial statements' users about qualitative financial reporting in Albania and the qualitative characteristic of faithful representation. 
Table 2: Results of the model for Faithful Representation (Second Qualitative Characteristic)

\begin{tabular}{ccccc}
\hline Model & $\begin{array}{c}\mathrm{R} \text { (Coefficient of } \\
\text { Correlation) }\end{array}$ & $\begin{array}{c}\mathbf{R}^{2} \text { (Coefficient of } \\
\text { Determination) }\end{array}$ & $\begin{array}{c}\text { Adjusted R } \\
\text { Square }\end{array}$ & $\begin{array}{c}\text { Std. Error of the } \\
\text { Estimate }\end{array}$ \\
\hline 1 & 0.903 & $\mathbf{0 . 8 1 5}$ & 0.754 & 0.54429 \\
\hline
\end{tabular}

\section{Source: Authors}

Correlation coefficient $\mathrm{R}=0.903$; correlation coefficients whose magnitude is between 0.9 and 1.0 indicate that the variables have very strong and positive correlations. So, we conclude that according to the results of this applied regression model there is a very strong correlation or a very functional relationship between the perception that users of financial reporting have for their qualitative financial reporting and the fundamental characteristic of faithful representation. The coefficient of determination $R_{2}=0.815$, meaning $81.5 \%$ of users' perception of the qualitative financial reporting is attributed to the qualitative characteristic of faithful representation. This indicator also shows that the connection between variables is strong and significant. The attitude of users towards this feature is also very positive. This characteristic is linked to the acceptance of the following statements: the presence of explanatory notes to the assumptions and estimates made clearly; also for the selection of accounting principles, highlighting the positive and negative events during the discussion of the annual results, the presence of an unqualified auditor report and the existence of information on the governance issues of the entities.

\subsection{Qualitative Characteristic of Comparability}

Ho: There is no significant relationship between the perception of users about quality of financial reporting in Albania and the qualitative characteristic of comparability.

$\mathrm{H}$ : There is a significant relationship between the perception of users about quality of financial reporting in Albania and the qualitative characteristic of comparability.

Table 3: Results of the model for Comparability (Third Qualitative Characteristic)

\begin{tabular}{ccccc}
\hline Model & $\begin{array}{c}\text { R(Coefficient of } \\
\text { Correlation) }\end{array}$ & $\begin{array}{c}\mathbf{R}^{2} \text { (Coefficient of } \\
\text { Determination) }\end{array}$ & $\begin{array}{c}\text { Adjusted R } \\
\text { Square }\end{array}$ & $\begin{array}{c}\text { Std. Error of the } \\
\text { Estimate }\end{array}$ \\
\hline 1 & 0.826 & $\mathbf{0 . 6 8 2}$ & 0.654 & 0.56363 \\
\hline
\end{tabular}

Source: Author

Correlation coefficient $\mathrm{R}=0.826$; correlation coefficients whose magnitude are between 0.7 and 0.9 indicate that the variables have strong and positive correlations. We conclude that there is a strong correlation or functional link between the perception that users of financial reporting have for qualitative financial reporting and qualitative characteristic of comparability. Coefficient of determination $\mathrm{R}_{2}=0.682$. The coefficient of determination shows what percentage of the dependent variable is expressed through the independent one. In our case $68.2 \%$ of users' perception of financial reporting about qualitative financial reporting is attributed to the qualitative characteristic of comparability. This value indicates that the link is strong and meaningful. So users hold a positive attitude towards improving the quality of comparability feature. The presence of this feature is acknowledged by the statements: the presence of records of changes in accounting policies and the changes that result from these changes, comparability with the results of previous accounting periods, and information provided by other organizations. 


\subsection{Qualitative Characteristic of Timeliness}

Ho: There is no significant relationship between the perception of users about quality of financial reporting in Albania and the qualitative characteristic of timeliness.

$\mathrm{H}_{1}$ : There is a significant relationship between the perception of users about quality of financial reporting in Albania and the qualitative characteristic of timeliness.

Table 4: Results of the model for Timeliness (Fourth Qualitative Characteristic)

\begin{tabular}{ccccc}
\hline Model & $\begin{array}{c}\text { R( Coefficient of } \\
\text { Correlation) }\end{array}$ & $\begin{array}{c}\mathbf{R}^{2} \text { (Coefficient of } \\
\text { Determination) }\end{array}$ & $\begin{array}{c}\text { Adjusted R } \\
\text { Square }\end{array}$ & $\begin{array}{c}\text { Std. Error of the } \\
\text { Estimate }\end{array}$ \\
\hline 1 & 0.716 & $\mathbf{0 . 5 1 3}$ & 0.497 & 0.57431 \\
\hline
\end{tabular}

\section{Source: Author}

Correlation coefficient $\mathrm{R}=0.716$; correlation coefficients whose magnitude are between 0.7 and 0.9 indicate that the variables have strong and positive correlations. From this results above we conclude that there is a functional and strong connection between users' perception of reports and the qualitative characteristic of comparability. Coefficient of determination $\mathrm{R}^{2}=0.513$. Statistical measures show that $51.3 \%$ of the perception of users of financial statements in Albania is attributed to the characteristic of timeliness for published information in annual reports, resulting in a not strong positive attitude compared to the above characteristics, but we can also mention that the trend remains positive. Furthermore, preparers of financial reports should focus more on improving this attribute. More specifically, this feature is presented in the acceptance of the statement that the annual reports are published in a timely manner.

\subsection{Qualitative Characteristic of Understandability}

Ho: There is no significant relationship between the perception of users about quality of financial reporting in Albania and the qualitative characteristic of understandability.

$\mathrm{H}$ : There is a significant relationship between the perception of users about quality of financial reporting in Albania and the qualitative characteristic of understandability.

Table 5: Results of the model for Understandability (Fifth Qualitative Characteristic)

\begin{tabular}{ccccc}
\hline Model & $\begin{array}{c}\text { R( Coefficient of } \\
\text { Correlation) }\end{array}$ & $\begin{array}{c}\mathbf{R}^{2} \text { (Coefficient of } \\
\text { Determination) }\end{array}$ & $\begin{array}{c}\text { Adjusted R } \\
\text { Square }\end{array}$ & $\begin{array}{c}\text { Std. Error of the } \\
\text { Estimate }\end{array}$ \\
\hline 1 & 0.885 & $\mathbf{0 . 7 8 4}$ & $\mathbf{0 . 7 2 1}$ & 0.55888 \\
\hline
\end{tabular}

\section{Source: Author}

The correlation coefficient $\mathrm{R}=0.885$, correlation coefficients whose magnitude are between 0.7 and 0.9 show that the variables have strong and positive correlations. This result will be interpreted in the same, way as above characteristics, the relationship between the dependent variable $\mathrm{Y}$ and the independent variable $\mathrm{X}$, according to these results there is a strong and functional relationship. On the other hand, it turns out that the coefficient of determination is $R_{2}=0.784$. The determination coefficient indicates what percentage of the independent variable is attributed to the dependent variable or in other words how much the dependent variable is expressed through the independent variable. According to the results, we conclude that $78.4 \%$ of users' perception of qualitative financial reporting in the annual financial reports, is attributed to the qualitative characteristic of understandability. More specifically accepted by the statements: good organization of financial 
reporting, the presence of clear notes in the financial performance statements and financial position and an understanding of the sources and level of expenses reported.

\subsection{Qualitative Characteristic of Verifiability}

Ho: There is no significant relationship between the perception of users about quality of financial reporting in Albania and the qualitative characteristic of verifiability.

$\mathrm{H}_{1}$ : There is a significant relationship between the perception of users about quality of financial reporting in Albania and the qualitative characteristic of verifiability.

Table 6: Results of the model for Verifiability (Sixth Qualitative Characteristic)

\begin{tabular}{ccccc}
\hline Model & $\begin{array}{c}\mathrm{R} \text { ( Coefficient of } \\
\text { Correlation) }\end{array}$ & $\begin{array}{c}\mathbf{R}^{2} \text { (Coefficient of } \\
\text { Determination) }\end{array}$ & $\begin{array}{c}\text { Adjusted R } \\
\text { Square }\end{array}$ & $\begin{array}{c}\text { Std. Error of the } \\
\text { Estimate }\end{array}$ \\
\hline 1 & 0.757 & $\mathbf{0 . 5 7 3}$ & 0.524 & 0.57439 \\
\hline
\end{tabular}

\section{Source: Author}

Correlation coefficient $\mathrm{R}=0.757$; correlation coefficients whose magnitude is between 0.7 and 0.9 indicate that the variables have strong and positive correlations. From this table it results that the coefficient of determination $\mathrm{R}_{2}=0.573$. The coefficient of determination shows once again what percentage of the dependent variable is expressed through the independent one. In this case $57.3 \%$ of users' perception of qualitative financial reporting is attributed to the qualitative characteristics of verifiability. This value indicates that the relationship is not very strong. More specifically, this feature is presented in the acceptance of the statement that the annual reports are verified and evaluated by the external audit.

Generally, users of financial information in Albania considered the qualitative characteristics to be important towards the quality of financial reporting. The relationship between faithful representation and the quality of financial reporting was the strongest relationship considered by Albanian users of financial information $(\mathrm{R}=0.903)$. The other qualitative characteristics such as understandability $(\mathrm{R}=0.885)$, relevance $(\mathrm{R}=0.861)$, comparability $(\mathrm{R}=0.826)$, verifiability $(\mathrm{R}=$ o.757), timeliness $(R=0.716)$ also are considered to be important on increasing quality of financial reporting in Albania.

Timeliness appears to be considered the less imperative, and verifiability status the second one to be considered as less imperative. Usually this is related to the Albanian rules with respect to financial statements related reports and the obligatory necessities for audit reports. The literature review, mostly shows the qualitative characteristic of timeliness to be the less critical in users' discernments for quality of financial reporting, but in Albanian users 'perception the qualitative characteristic of verifiability also appeared to be in questionable status and to be considered less critical.

\section{Conclusions}

The main purpose of financial reporting is to produce useful financial information that is important for decision making. This paper considered how qualitative characteristics can be operationalized to enable the measurement of the quality of financial reporting. This operationalization of the quality of financial reporting in terms of fundamental and improving quality characteristics was first defined by the IFRS and FASB Conceptual Framework. In this context, two categorizations of characteristics were made: fundamental characteristics such as relevance and faithful representation, as well as qualitative characteristics such as comparability, timeliness, understandability and verifiability of accounting information. To achieve this objective, a survey is used to assess the perception of users of 
financial reports in Albania. This is achieved by listing the attributes of each qualitative characteristic to determine how much they improve the quality of financial report. The results of the analysis for relevance showed that according to users "perception "the quality of financial reports published in Albania is significantly related to the qualitative characteristic of relevance". The results of the analysis for faithful representation characteristic shows that according to users 'perception "the quality of financial reports published in Albania is strongly and significantly related to the qualitative characteristic of faithful representation". The results of the analysis for comparability characteristic showed that according to users 'perception "the quality of financial reports published in Albania has a strong and significant relationship with the qualitative characteristic of comparability. The results of the analysis for the characteristic of timeliness showed that according to users "perception "the quality of financial reporting is moderately strongly related to the qualitative characteristic of timeliness". The results of the analysis for the characteristic of understandability showed that according to users 'perception the quality of financial reports published in Albania is significantly related to the characteristic of understandability. The results of the analysis for the last characteristic of verifiability according to users 'perception showed that "the quality of financial reports published in Albania is moderately related to the qualitative characteristic of verifiability. This paper found that users of financial reports in Albania generally have a very positive attitude towards the qualitative characteristics of financial reporting. The characteristic of faithful representation is evaluated as a more significant characteristic of financial information, followed by the relevance, comparability and understandability of the information presented in these reports. Specifically, the results of this study indicate that managers of Albanian companies need to improve the timeliness of financial information and the issuance of financial reports to improve the quality of financial reports and increase the usefulness of decision-making reports to accounts for users. Albanian government agencies and regulatory agencies are also encouraged to strengthen their supervisory functions to ensure that Albanian economic entities improve their compliance with IFRS standards to make useful decisions. It is also necessary to strengthen the training and education of users without accounting training. This will help them improve their perception, evaluation and understanding of financial information in the period we are living. Finally, we suggest that future research can be conducted in this aspect of financial information quality assessment, and may involve the views of financial statement preparers, not just the views of users, in order to provide a more in-depth view of this topic.

\section{References}

Aifuwa, H. Embele, K. Saidu, M. (2018). Ethical accounting practices and financial reporting quality, International Journal of Multidisciplinary Research, 4(12), 31-44.

Al-dmour, A., Abbod, MF., Al-Dmour, HH. (2017). Qualitative Characteristics of Financial Reporting and Non Financial Business Performance, International Journal of Corporate Finance and Accounting, 4(2), 1-22.

Barth, M. E., Beaver, W. H., \& Landsman, W. R. (2001). The relevance of the value relevance literature for financial accounting standard setting: another view. Journal of Accounting and Economics 31(1-3), 77-104.

Beest, F., Braam, G., Boelens, S., (2009). Quality of Financial Reporting: measuring qualitative characteristics. Nijmegen Center for Economics, o9-108.

Chen, A., Gong, J. J., (2019). Accounting comparability, financial reporting quality, and the pricing of accruals. Advances in accounting, Elsevier. Vol. 45(C), pages 1-1.

Cuong, N. T., \& Ly, D. T. (2017). Measuring and Assessing the Quality of Information on the Annual Reports: The Case of Seafood's Companies Listed on the Vietnam Stock Market. International Research Journal of Finance and Economics, Issue 16o, 26-40.

Deloitte Albania (2018), Survey on Financial Reporting in Albania, Raising the Awareness on the Benefits of Good Financial Reporting, User Survey, 6-12.

FASB. (2008). Statement of Financial Accounting Concepts No. 1 and 2. Financial Accounting Standards Board.

Hasan, S N., Abdullah, S Z., Hossain, (2014). Qualitative Characteristics of Financial Reporting - An Evaluation of Users'Perception in Bangladesh. The Pakistan Accountant, Issue 1-3, 23-31.

IFRS. (2010). The Conceptual Framework for Financial Reporting. IFRS Foundation. 
Jonas, G. J., \& Blanchet, J. (2000). Assessing Quality of Financial Reporting. America: Accounting Horizons.

Krupka, Y., Muzyka, M. (2017). On qualitative characteristics of financial reporting. Herald of Ternopil National Economic University. 3(85), 97-106.

Kythreotis, A. (2014). Measurement of financial reporting quality based on IFRS conceptual framework's fundamental qualitative characteristics, European Journal of Accounting, Finance \& Business, vol 2 (3), 4-29.

MH Maher, MS Fakhar and SM Jafari (2015), Examination of the Managers' Attitudes towards the Quality of the Presented Financial Reports: A Case Study. Journal of Health Management and Informatics, 2(2), 56-62.

Mbawuni, J., (2019). Users' Perception of Financial Reporting Quality in Ghana. Accounting and Finance Research. $8(3), 187-200$.

Mbobo, M., Ekpo, N. B., (2016), Operationalising the Qualitative Characteristics of Financial Reporting. International Journal of Finance and Accounting, 5(4),184-192.

McDaniel, L., Martin, R. D., \& Maines, L. A. (2002). Evaluating Financial ReportingQuality: The Effects of FinancialExpertise vs. Financial Literacy. The accounting review, 77(1), 139-167.

Morosan-Danila, L., Grigoras, C E., (2016). Hierarchy of accounting information qualitative characteristics in financial reporting. The USV Annals of Economics and Public Administration. 16, 183-191.

Mohd Hussin, S., Zainol, S., Tengku Arifin, T., \& Samsuri, A. (2021). Qualitative Characteristics of Financial Information Toward Quality of Financial Reporting in Malaysian Listed Manufacturing Firms. Asian Journal Of Research In Business And Management, 3(2), 102-111.

Obaidat, A. N. (2007). Accounting Information Qualitative Characteristics Gap: Evidence from Jordan Vol. 3 No. 2. International Management Review, vol 3(2), 26-32.

Pounder, B. (2013). Financial Accounting Quality, SEA Practical Aplication of Science 3(5), 93-98.

Rostami, V., \& Saleh, M. (2011). Necessity for reengineering the qualitative characteristics of financial reporting arrangement in the reduction of information asymmetry: An evidence of Iran. African Journal of Business Management, $5(8)$, 3274-3288.

Rostami, V., \& Salehi, M. (2011). Necessity for reengineering the qualitative. African Journal of Business Management Vol.5 (8), 3274-3288.

Soyinka, K.A., Fagbayimu, M. O., Adegoroye E., Ogunmola, J. O., (2017). Decision Usefulness and Financial Reporting: The General Public Perspective. International Journal of Academic Research in Accounting, Finance and Management Sciences, 160-168.

Tasios, S., (2012). Auditor's perceptions of financial reporting quality: the case of Greece. International Journal of Accounting and Financial Reporting 2(1), 57-74.

Tsoncheva, G. (2014). MEASURING AND ASSESSING THE QUALITY AND USEFULNESS OF ACCOUNTING INFORMATION. Journal of University of Economics - Varna, 52-64.

Vokshi, N. B., Krasniqi, Xh. F., (2017). Role of Accounting Information in Decision-Making Process, the Importance for its Users, Entrenova, 7(9), 324-331

Zheng, X., Chen, J., (2017). Financial reporting quality in China: A perspective of qualitative characteristics. Transformations in Business and Economics. 16(3), 148-163. 